\title{
Ovarian conservation in adnexal torsion-a report of six cases
}

\author{
C. E. North • L. G. Nardo • T. Mokate • E. Edi-Osagie • \\ R. K. A. Naidoo • A. R. B. Smith
}

Received: 21 January 2007 / Accepted: 18 July 2007 / Published online: 16 August 2007

(C) Springer-Verlag 2007

\begin{abstract}
Adnexal torsion is an uncommon but important cause of emergency admission to the gynaecologist. Treatment of adnexal torsion has traditionally involved surgical excision of the affected structure, usually via laparotomy. A more conservative surgical approach of untwisting the torsion has been widely reported in paediatric cases. Despite reports of the successful treatment of torsion with this approach in the adult population, many UK surgeons remain reluctant to attempt ovarian conserving surgery, particularly via the laparoscopic route.We report six cases of conservative surgery for adnexal torsion. After initial success via laparotomy, the subsequent five cases were managed laparoscopically. We discuss the advantages and disadvantages of this management approach.
\end{abstract}

Keywords Adnexal torsion - Ovarian torsion - Ovarian conservation · Laparoscopy · Ovarian cyst

C. E. North $(\bowtie) \cdot$ A. R. B. Smith

Department of Urogynaecology, Saint Mary's Hospital,

Whitworth Park,

Manchester, United Kingdom

e-mail: Carolyn.north@ntlworld.com

L. G. Nardo

Department of Reproductive Medicine, Saint Mary's Hospital,

Whitworth Park,

Manchester, United Kingdom

T. Mokate $\cdot$ E. Edi-Osagie $\cdot$ R. K. A. Naidoo

Saint Mary's Hospital,

Whitworth Park,

Manchester, United Kingdom

\section{Introduction}

Adnexal torsion is an uncommon but important cause of emergency admission to the gynaecology unit, accounting for approximately $3 \%$ of emergency gynaecological surgery [1]. Although most common in the reproductive years, up to $15 \%$ of torsion occurs in pre-pubertal children [2]. The most common presenting symptoms are pain, nausea and vomiting [1,3-5]. Between 60 and $80 \%$ of patients will have a palpable abdominal mass [3, 4]. Low grade fever and leucocytosis may occur. In most cases, symptoms are present for several days before medical attention is sought.

Following presentation, difficulties in making an accurate diagnosis often lead to delays in receiving appropriate treatment. Accuracy of clinical diagnosis is poor, although the correct diagnosis of adnexal torsion is more likely to be made in pregnant rather than non-pregnant patients $[1,6,7]$. Ultrasound imaging usually aids diagnosis of torsion. Furthermore, abnormalities of ovarian perfusion can be demonstrated with Doppler sonography [8-12]. Normal blood flow does not exclude torsion and a lack of flow can occur in other ovarian conditions. The development of threedimensional sonography may enhance the diagnostic potential of ultrasound [13]. It has also been suggested that magnetic resonance imaging (MRI) has a role in assessing ovarian viability in cases of torsion $[14,15]$.

Adnexal torsion is more common on the right side $[1,4]$. Although an ovarian mass is widely believed to be the precipitating cause, torsion may occur in apparently normal adnexum, particularly in children. In cases where an adnexal abnormality is present, para-ovarian and para-tubal masses are most likely to be encountered. A benign dermoid cyst is the most common ovarian mass to undergo torsion. Benign masses are more likely to undergo torsion and malignancy is found in less than $5 \%$ of torsions $[1,16,17]$. 
Treatment of adnexal torsion has traditionally involved surgical excision of the affected structure, usually via laparotomy. Surgeons have been reluctant to untwist the torsion due to concerns that this will result in an embolus from thrombosed veins [1], although this complication has not been reported. A more conservative surgical approach of untwisting the torsion has been widely reported in paediatric cases. Despite reports of successful treatment of torsion with this approach in the adult population, many surgeons in the UK remain reluctant to attempt ovarian conserving surgery, particularly via the laparoscopic route. We present a series of six cases of conservative surgery for adnexal torsion in women of reproductive age. After initial successful ovarian conservation via laparotomy, the subsequent five cases were managed laparoscopically. The advantages and disadvantages of this management approach are discussed.

\section{Description of the cases}

\section{Case one}

A 14-year-old, Caucasian patient presented to the emergency department with a 7-day history of back and left iliac fossa pain. She had never been sexually active and had no significant past gynaecological history. Ultrasound scanning confirmed a left adnexal simple cyst measuring $5.1 \times 7 \times 4.6 \mathrm{~cm}$ and a partly solid, partly cystic mass measuring $9.1 \times 6.6 \times 8 \mathrm{~cm}$. Laparotomy was recommended as a result of escalating analgesic requirements.

At laparotomy the left ovary was found to be enlarged by haemorrhage and a para-tubal cyst was also present. Both were torted twice (see Fig. 1). After de-torsion, the para-tubal cyst was excised and the tubal mesentery repaired. The ovary was tacked to the pelvic side wall with a Vicryl suture.

The patient made an uneventful recovery and was discharged home on the 4th post-operative day.

\section{Case two}

A 22-year-old, Caucasian patient presented to the emergency department at 12 weeks into her third pregnancy. She had previously experienced one first trimester miscarriage and one first trimester termination of pregnancy. She complained of left iliac fossa pain with no vaginal loss. Trans-abdominal ultrasound confirmed a viable pregnancy, but also demonstrated two simple cysts within the left adnexum measuring $6.5 \times 5.6 \times 4.9 \mathrm{~cm}$ and $6.4 \times 5.7 \times 5.2 \mathrm{~cm}$. The right ovary appeared normal.

Conservative management, with admission for rest and analgesia, was advised. On the 6th day of admission, her

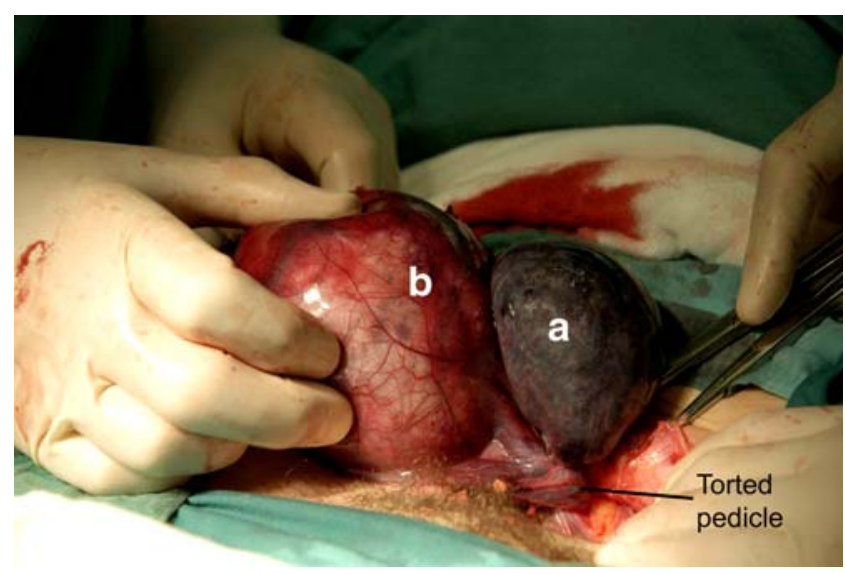

Fig. 1 Photograph, taken at laparotomy, showing the torted, black, oedematous ovary (a) and a para-tubal cyst (b). The torsion can be clearly seen inferiorly, as indicated by the black line

condition deteriorated with increased pain and signs of peritonism. A laparoscopy was performed which revealed distension of the left fallopian tube with a haemorrhagic tubal cyst. The left ovary was enlarged by a haemorrhagic ovarian cyst. Both the tube and ovary were torted twice. After laparoscopic de-torsion, the cysts were drained and the ovarian cyst wall removed. The ovary was reconstructed with intra-corporeal Vicryl sutures and then tacked to the pelvic side wall with an Ethibond suture.

The patient was discharged home on the 2 nd postoperative day. A repeat ultrasound at 14 weeks of pregnancy revealed recurrent cysts within the left adnexa measuring $3.7 \times 3.4 \times 4.5 \mathrm{~cm}$ and $4.1 \times 3.0 \times 4.1 \mathrm{~cm}$. These were asymptomatic and the remainder of her pregnancy passed uneventfully. She delivered a 3,480-g female infant by ventouse following spontaneous labour at 41 weeks.

\section{Case three}

A 24-year-old, Caucasian patient presented to the emergency department 13 weeks into her first pregnancy. She had booked for antenatal care at another hospital where her booking scan at 9 weeks gestation had apparently revealed bilateral ovarian cysts measuring $14 \mathrm{~cm}$ on the left and $4 \mathrm{~cm}$ on the right. An admission for elective laparotomy and cystectomy had been arranged and was due to be performed at 14 weeks' gestation.

However, she had developed left-sided abdominal pain and trans-abdominal scan revealed a viable foetus and confirmed bilateral ovarian cysts. The right ovary had a volume of $84 \mathrm{cc}$ and contained multiple cysts, the largest measuring $3.1 \times 3.1 \times 3.8 \mathrm{~cm}$. The left ovary contained a single, multi-loculated cyst measuring $16.2 \times 5.8 \times 13.3 \mathrm{~cm}$.

A laparoscopy was performed which revealed two simple cysts in the left ovary. The ovary and tube had torted once. The right adnexa could not be visualised behind the gravid uterus. After laparoscopic de-torsion, both cysts 
were drained and the cyst walls excised. Ovarian reconstruction was not required and the ovary was tacked to the pelvic side wall with an Ethibond suture.

The patient made an uneventful recovery and was discharged home on the 2nd post-operative day. She represented to the emergency department at 24 weeks' gestation with a recurrence of her left-sided abdominal pain. Trans-abdominal ultrasound revealed a left ovarian cyst measuring $4.8 \times 6.8 \times 6.8 \mathrm{~cm}$. Repeat surgical management was declined by the patient and she underwent ultrasound-guided aspiration of the cyst. This provided symptomatic relief and she was discharged home.

At 35 weeks' gestation, she again presented with abdominal pain and a recurrent left ovarian cyst measuring $10 \times 10 \times 5 \mathrm{~cm}$. She was managed conservatively until her pregnancy reached the 36 th week when an elective caesarean section was performed under spinal anaesthesia. A 2,930-g male infant was delivered. Bilateral, simple ovarian cysts were excised at the time of surgery, neither demonstrating any evidence of torsion nor haemorrhage.

\section{Case four}

A 30-year-old Asian patient presented to the emergency department complaining of abdominal pain. She had previously delivered two children vaginally and had been found to have a positive pregnancy test the week before. Oligomenorrhoea, possibly due to her history of hyperprolactinaemia, meant that her dates were uncertain. Serum ßhCG level was approximately 1,500 IU/1 and transvaginal ultrasound failed to demonstrate an intra-uterine pregnancy. Instead, a mass was seen in the left adnexum measuring $4.1 \times 2.4 \times 5.1 \mathrm{~cm}$ with free fluid in the pouch of Douglas. The right adnexum appeared to contain an ovarian cyst measuring $8.1 \times 6.6 \times 5.4 \mathrm{~cm}$.

At laparoscopy, the right ovary was found to be distended with a simple cyst and had torted once. The right Fallopian tube appeared abnormal and was distended with haemorrhage. After laparoscopic de-torsion of the ovarian cyst, a laparoscopic salpingectomy was performed given suspicions of an ectopic gestation. The ovarian cyst was drained and the ovary tacked to the pelvic side wall.

The patient made an uneventful initial recovery, with rapidly declining serum $\beta$ hCG levels and was, therefore, discharged on the 3 rd post-operative day. Histopathological examination of the excised tube revealed no trophoblastic tissue, only haemorrhagic infarction.

Two weeks after her discharge from hospital, the patient presented to the emergency department with recurrent abdominal pain. Trans-abdominal ultrasound revealed a left ovarian cyst measuring $5.5 \times 4.4 \times 2.8 \mathrm{~cm}$ and a large haemorrhagic mass in the right adnexum with a volume of $252 \mathrm{cc}$. At laparotomy, a simple cyst of the left ovary was excised. The conserved right ovary was enlarged and necrotic. An oophorectomy was, therefore, performed.

Case five

A 23-year-old, Caucasian patient presented to the emergency department 17 weeks into her first pregnancy. She complained of vague abdominal pain and trans-abdominal ultrasound revealed a right adnexal mass measuring $9.3 \times$ $7.4 \times 7.5 \mathrm{~cm}$. She was allowed home but returned 3 days after her scan with increased right iliac fossa pain and signs of peritonism. The ultrasound findings were unchanged.

A laparoscopy was performed, initially utilising a left hypochondrial port as the 17 -week uterus was filling the pelvis. The right ovary was found to be enlarged with a $10-\mathrm{cm}$ dermoid cyst and was torted twice. After laparoscopic detorsion, the cyst was drained and the cyst wall excised. The ovary was left open given satisfactory haemostasis and tacked to the pelvic side wall with an Ethibond suture.

The patient made an uneventful recovery and was discharged home on the 2 nd post-operative day. At her routine foetal anomaly scan, performed at 20 weeks of pregnancy, a right adnexal cyst measuring $6 \times 5.4 \times 5.2 \mathrm{~cm}$ was noted but was asymptomatic. Following induction of labour for post-maturity, she delivered a healthy, 3,340 g male infant by normal vaginal delivery.

\section{Case six}

A 20-year-old, nulliparous, Caucasian patient presented to the emergency department with a 4-day history of right iliac fossa pain. A pregnancy test was negative and she was admitted under the care of the general surgeons with possible appendicitis. Trans-vaginal ultrasound scanning the following day revealed a right adnexal mass, with a mean diameter of $6.5 \mathrm{~cm}$, and her care was transferred to the gynaecology team.

On the 3rd day of her admission, a laparoscopy was performed which confirmed the right ovarian mass with appearances consistent with a dermoid cyst. The right tube and ovary were twisted once. After de-torsion, the cyst was excised laparoscopically. Ovariopexy was not performed and ovarian reconstruction was not required.

The patient made an uneventful recovery and was discharged home on the 2 nd post-operative day.

\section{Case follow-up}

Following surgery, the patients have been followed-up with a repeat ultrasound scan and Doppler studies, which were performed by the same clinician in all cases. The time interval from surgery to post-operative ultrasonography ranged from 6 to 18 months. At the follow-up visit, all 
patients were asymptomatic and reported regular menstrual periods. The ultrasound findings and a summary of each case from admission are shown in Table 1.

\section{Discussion}

The first case in this series was performed on the recommendation of Dr Valentino Bergamini from Verona who was visiting the senior author's (ARBS) operating theatre in Manchester. A 14-year-old girl presented with abdominal pain due to a torted adnexum secondary to a para-tubal cyst as illustrated in the photograph. The ovary is seen to be oedematous and discoloured. The quick, uneventful recovery from conservative surgery and the subsequent ultrasonic evidence of normal ovarian function encouraged the authors to employ conservative management of ovarian torsion in emergency cases which have since presented to the hospital.

Conservative management of ovarian torsion has previously been described in a number of articles but not from surgeons based in the United Kingdom. Novak's textbook of gynaecology [18] reads "The management of suspected ovarian torsion, which can occur at any age, from prepubertal to postmenopausal, is surgical. Previous studies have suggested that ovarian torsion requires oophorectomy on the basis that untwisting of the ovarian pedicle would lead to emboli. Recent studies have suggested that the primary management should be detorsion with ovarian cystectomy; if a cyst is present, normal ovarian function frequently results even in ovaries that do not initially appear to be viable. This management is particularly important in prepubertal and young women. Oophoropexy may be helpful in preventing recurrent torsion".

The main immediate concern when monitoring the recovery from conservative surgery is whether necrosis and sepsis develop. In this small series such complications did develop in one case possibly because the ovarian blood supply was further compromised by the diathermy and excision of the Fallopian tube on the same side (removed because of the possibility of an ectopic pregnancy). Nardo et al. [19] have demonstrated that tubal excision may compromise the ovarian vasculature, thus influencing future ovarian function. The literature on conservative treatment of ovarian torsion does not provide any insight into the aetiology or frequency of this complication.

Table 1 Follow-up ultrasound findings and summary of each case's characteristics

\begin{tabular}{|c|c|c|c|c|c|}
\hline Cases & Pre-surgery USS & Surgical procedure & Histology & Readmissions & Post-surgery USS \\
\hline 1 & $\begin{array}{l}\text { R ovary: normal } \\
\text { L ovary: cyst } 9.1 \times 6.6 \times 8 \mathrm{~cm} \\
\text { L paratubal cyst } 5.1 \times 7 \times 4.6 \mathrm{~cm}\end{array}$ & $\begin{array}{l}\text { Laparotomy-paratubal cyst } \\
\text { excision and detorsion of left } \\
\text { adnexum } \times 2\end{array}$ & Paratubal cyst & No & $\begin{array}{l}\text { R ovary: } 3.2 \times 2.6 \times 2.1 \mathrm{~cm} \\
R I=0.55 \\
\text { L ovary: } 2.9 \times 2.5 \times 2.0 \mathrm{~cm} \\
\text { RI }=0.51\end{array}$ \\
\hline 2 & $\begin{array}{l}\text { 12-week viable singleton } \\
\text { pregnancy R ovary: normal } \\
\text { L ovary: cysts } 6.5 \times 5.6 \times 4.9 \mathrm{~cm} \\
\text { and } 6.4 \times 5.7 \times 5.2 \mathrm{~cm}\end{array}$ & $\begin{array}{l}\text { Laparoscopy-detorsion of left } \\
\text { ovary and para-tubal cyst. } \\
\text { Cystectomy and left } \\
\text { ovariopexy }\end{array}$ & $\begin{array}{l}\text { Haemorrhagic } \\
\text { and infarcted } \\
\text { tissue }\end{array}$ & No & $\begin{array}{l}\text { R ovary } 71 \mathrm{cc} \text { and contains } \\
\text { follicles } \\
\text { RI refused } \\
\text { L ovary not clearly seen- } \\
\text { rescan refused }\end{array}$ \\
\hline 3 & $\begin{array}{l}\text { 13-week viable singleton } \\
\text { pregnancy; R ovary: cyst } 3.1 \times \\
3.1 \times 3.8 \mathrm{~cm} \text {; L ovary: cyst } 16.2 \times \\
5.8 \times 13.3 \mathrm{~cm}\end{array}$ & $\begin{array}{l}\text { Laparoscopy-ovarian cyst } \\
\text { aspiration, detorsion of left } \\
\text { ovary and cystectomy. Left } \\
\text { ovariopexy }\end{array}$ & $\begin{array}{l}\text { Mucinous } \\
\text { cystadenoma }\end{array}$ & $\begin{array}{l}\text { Yes-USS- } \\
\text { guided } \\
\text { aspiration of } \\
\text { left ovarian } \\
\text { cyst }\end{array}$ & $\begin{array}{c}\text { R ovary: } 4.0 \times 3.0 \times 1.7 \mathrm{~cm} \\
R I=0.54 \text { L ovary: } 3.2 \times \\
2.6 \times 2.8 \mathrm{~cm} \mathrm{RI}=0.57\end{array}$ \\
\hline 4 & $\begin{array}{l}\text { R adnexum: cystic structure } 8.1 \times \\
6.6 \times 5.4 \mathrm{~cm} \\
\text { L ovary: } 4.1 \times 2.4 \times 5.1 \mathrm{~cm}\end{array}$ & $\begin{array}{l}\text { Laparoscopy-right } \\
\text { salpingectomy and ovariopexy }\end{array}$ & $\begin{array}{l}\text { Haemorrhagic } \\
\text { infarction of } \\
\text { right fallopian } \\
\text { tube }\end{array}$ & $\begin{array}{l}\text { Yes- } \\
\text { laparotomy } \\
\text { right } \\
\text { oophorectomy }\end{array}$ & $\begin{array}{l}\text { R ovary: absent } \\
\text { L ovary: } 3.2 \times 2.4 \times 2.8 \mathrm{~m} \\
\mathrm{RI}=60\end{array}$ \\
\hline 5 & $\begin{array}{l}17 \text {-week viable singleton } \\
\text { pregnancy } \\
\text { R ovary: cyst } 9.3 \times 7.4 \times 7.5 \mathrm{~cm} \\
\text { L ovary: normal }\end{array}$ & $\begin{array}{l}\text { Laparoscopy-detorsion of right } \\
\text { ovary and cystectomy. Right } \\
\text { ovariopexy }\end{array}$ & $\begin{array}{l}\text { Mature cystic } \\
\text { teratoma }\end{array}$ & No & $\begin{array}{l}\text { R ovary: } 3.0 \times 3.3 \times 2.1 \mathrm{~cm} \\
R I=0.54 \\
L \text { ovary: } 2.6 \times 2.2 \times 2.2 \mathrm{~cm} \\
\mathrm{RI}=0.59\end{array}$ \\
\hline 6 & $\begin{array}{l}\text { R ovary: cyst diameter } 6.5 \mathrm{~cm} \\
\text { L ovary: normal }\end{array}$ & $\begin{array}{l}\text { Laparoscopy-detorsion of right } \\
\text { cyst and tube. Cystectomy }\end{array}$ & $\begin{array}{l}\text { Mature cystic } \\
\text { teratoma }\end{array}$ & No & $\begin{array}{l}\text { R ovary: } 2.6 \times 2.2 \times 1.8 \mathrm{~cm} \\
\text { RI=0.49 } \\
\text { L ovary: } 3.1 \times 3.0 \times 2.2 \mathrm{~cm} \\
\text { RI }=0.51\end{array}$ \\
\hline
\end{tabular}

$\mathrm{R}=$ right, $\mathrm{L}=$ left, $\mathrm{RI}=$ resistance index, $\mathrm{USS}=$ ultrasound scan 
There is no well-defined way of assessing ovarian viability in cases of ovarian torsion. Pre-operative Doppler studies have been employed whilst most surgeons rely on the colour and appearance of the ovary. In our series, some of the ovaries which were conserved appeared to be a blue colour and were very oedematous and congested at the time of surgery but were still viable on follow-up. The length of time of symptoms before surgery has been suggested as a guide to viability but some torsions have an intermittent history suggesting that the blood flow may vary rather than be acutely arrested. Evidence from published series suggests that neither Doppler flow studies nor appearance at surgery are reliable guides to long-term viability.

After the success of the first case, the authors employed laparoscopic surgery for release of the torsion in the other cases. This may lead to a shorter recovery but may make additional demands on the skills of the surgeon. In pregnancy, although torsion is most common in the first trimester, laparoscopic conservative management of torsion has been described in the 25th week of pregnancy [20]. However, the additional risks, particularly of avoiding uterine injury during the first port introduction, should not be underestimated and complications including pneumamnion and foetal loss have been reported [21].

It is not clear whether the addition of an ovarianstabilising suture is an important part of the procedure. Laparoscopic suturing, particularly when the space available, is reduced by the presence of a gravid uterus, can be difficult and may not be worth the additional struggle. The literature does not inform us on this issue although its use is widely recommended.

Ovarian conservation in cases of ovarian torsion appears to be an appropriate and safe management. Further research is required to define which cases are not suitable for this approach.

\section{References}

1. Hibbard LT (1985) Adnexal Torsion. Am J Obstet Gynecol 152:456-461

2. Adelman S, Benson CD, Hertzler JH (1975) Surgical lesions of the ovary in infancy and childhood. Surg Gynecol Obstet 141 (2):219-226
3. White M, Stella J (2005) Ovarian torsion: 10-year perspective. Emerg Med Australas 17(3):231-237

4. Lee CH, Raman S, Sivanesaratnam V (1989) Torsion of ovarian tumors: A clinicopathological study. Int J Gynaecol Obstet 28 (1):21-25

5. Houry D, Abbott JT (2001) Ovarian torsion: a 15-year review. Ann Emerg Med 38(2):156-159

6. Bider D et al (1991) Clinical, surgical and pathologic findings of adnexal torsion in pregnant and nonpregnant women. Surg Gynecol Obstet 173(5):363-366

7. Cohen SB et al (2001) Accuracy of the preoperative diagnosis in 100 emergency laparoscopies performed due to acute abdomen in nonpregnant women. J Am Assoc Gynecol Laparosc 8(1):92-94

8. Chang KH et al (1998) Conservative therapy of adnexal torsion employing color Doppler sonography. J Am Assoc Gynecol Laparosc 5(1):13-17

9. Lee EJ, Kwon HC, Joo HJ, Suh JH, Fleischer AC (1998) Diagnosis of ovarian torsion with color Doppler sonography: depiction of twisted vascular pedicle. J Ultrasound Med 17(2):83-89

10. Pena JE, Ufberg D, Cooney N, Denis AL (2000) Usefulness of Doppler sonography in the diagnosis of ovarian torsion. Fertil Steril 73(5):1047-1050

11. Albayram F, Hamper UM (2001) Ovarian and adnexal torsion: spectrum of sonographic findings with pathologic correlation. J Ultrasound Med 20(10):1083-1089

12. Ben-Ami M, Perlitz Y, Haddad S (2002) The effectiveness of spectral and color Doppler in predicting ovarian torsion. A prospective study. Eur J Obstet Gynecol Reprod Biol 104(1):64-66

13. Yaman C, Ebner T, Jesacher K (2002) Three-dimensional power Doppler in the diagnosis of ovarian torsion. Ultrasound Obstet Gynecol 20(5):513-515

14. Haque TL, Togashi K, Kobayashi H, Fujii S, Konishi J (2000) Adnexal torsion: MR imaging findings of viable ovary. Eur Radiol 10(12):1954-1957

15. Ghossain MA et al (2004) Adnexal torsion: magnetic resonance findings in the viable adnexa with emphasis on stromal ovarian appearance. J Magn Reson Imaging 20(3):451-462

16. Argenta PA, Yeagley TJ, Ott G, Sondheimer SJ (2000) Torsion of the uterine adnexa. Pathologic correlations and current management trends. J Reprod Med 45(10):831-836

17. Sommerville M, Grimes DA, Koonings PP, Campbell K (1991) Ovarian neoplasms and the risk of adnexal torsion. Am J Obstet Gynecol 164:577-578

18. Novak's Gynecology 2002, 13th Edition. In: Berek JS (ed) Published by Lippincott, Williams and Wilkins, Page 397

19. Gelbaya TA, Nardo LG, Fitzgerald CT, Horne G, Brison DR, Lieberman BA (2006) Ovarian response to gonadotrophins after laparoscopic salpingectomy or the division of fallopian tubes for hydrosalpinges. Fertil Steril 85(5):1464-1468

20. Bassil S, Steinhart U, Donnez J (1999) Successful laparoscopic management of adnexal torsion during week 25 of a twin pregnancy. Hum Reprod 14(3):855-857

21. Friedman JD, Ramsey PS, Ramin KD, Berry C (2002) Pneumoamnion and pregnancy loss after second trimester laparoscopic surgery. Obstet Gynecol 99:512-513 